\title{
Assaying the Relationship Between Resistivity and Concentration in Ocimumgratissium Flavor Extracted by Traditional and Conventional Methods
}

\author{
Uhiara Ngozi Sunday ${ }^{1, *}$, Onuoha Ogbonnaya Gideon ${ }^{1}$, Adesanya Oluwatosin Dorothy ${ }^{2}$, \\ Eduzor Esther ${ }^{1}$, Anayo Gabriel Jacob ${ }^{1}$, Adeosun Florence Funke ${ }^{2}$ \\ ${ }^{1}$ Department of Food Science and Technology, Federal Polytechnic Bauchi, Bauchi, Nigeria \\ ${ }^{2}$ Department of Nutrition and Dietetics, Federal Polytechnic Bauchi, Bauchi, Nigeria
}

Email address:

uhiarazi@yahoo.com (U. N. Sunday)

${ }^{*}$ Corresponding author

\section{To cite this article:}

Uhiara Ngozi Sunday, Onuoha Ogbonnaya Gideon, Adesanya Oluwatosin Dorothy, Eduzor Esther, Anayo Gabriel Jacob, Adeosun Florence Funke. Assaying the Relationship Between Resistivity and Concentration in Ocimumgratissium Flavor Extracted by Traditional and Conventional Methods. International Journal of Nutrition and Food Sciences. Vol. 10, No. 1, 2021, pp. 20-23.

doi: 10.11648/j.ijnfs.20211001.14

Received: November 17, 2020; Accepted: January 25, 2021; Published: February 23, 2021

\begin{abstract}
The extract of basil leave were prepared by two different methods; modification of an African cultural practice where specified weights in grams (between 100 and 300) of (non blemished, dust free) fresh basil leaves were harvested stalk free and heated (incinerated) stuffed in a clay earthenpot on a charcoal stove for nine (9) hours. The partially charred leaves were discarded and the pot thoroughly washed with $300 \mathrm{ml}$ distilled water. Finally, $200 \mathrm{ml}$ of distilled water was poured into the pot, covered and allowed to stand for 12 hours, before storing the water at $4^{\circ} \mathrm{C}$ in tightly sealed plastic containers, labeled as subunits of sample A. In the second procedure, basil leaves collected as in the first procedure were in separate batches stuffed into the distillation bottle with $200 \mathrm{ml}$ of distilled water. Distillation was carried out for 2 hours and distillates collected and stored in tightly sealed plastic bottle labeled as subunits of sample B. The samples (A and B) including their subunits were (within 30 minutes of extraction) subjected to spectrophotometry, $\mathrm{pH}$, and Total soluble solids (TSS) analysis. A 20 man trained panelist were employed in sensory evaluation of the (300g leaf) extracts (after storing at $4^{\circ} \mathrm{C}$ for 96 hours) in terms of colour, flavour, flavour interference and general acceptability. Furthermore, $20 \mathrm{ml}$ of each $(300 \mathrm{~g}$ leaf) extract of Aand B were poured into a curvet of $2 \mathrm{~mm}$ pathway. These were one after the other placed into an electric circuit with the poles submerged into opposite ends of the curvet. The following parameters were read from the meters when the circuit was completed: current, voltage and resistance to flow of electricity across the sample. Sample A (the extract made by the modified traditional practice) had the highest general acceptability compared to sample B and the natural leaf (control sample). It had significantly lower color and flavor interferences, with average of $8 / 10$ flavor intensity recording. Resistance to flow of electricity for both samples (A and B), were inversely proportional to leaf orflavour extract concentration with a gradient of 0.001 . It is therefore possible to compute concentrations of flavor components from resistance to flow of electricity with gradient and intercepts derived from graph (Figure 1). TSS, $\mathrm{pH}$ and temperature of samples followed the same pattern as electrical resistivity.
\end{abstract}

Keywords: Flavor, Extraction, Earthenware, Resistivity, Quantification

\section{Introduction}

'Nchuanwu' (Ocimumgratissium) is used extensively among the Igbos, not only for spicing of cultural pepper soup and various (meat) porridges but helping the relief of certain forms of stomach upsets. Scent leave or tea bush is also put into one use or the other by several other African groupscommonly for its anti inflammatory properties and pleasant fragrance due to its component of methyl eugenol, linol and terpinol all aromatic compounds [5, 6, 8]. Scent leave has also been associated with anti microbial (antifungal) properties as well as anxiolytic (ability to impact 
positively on anxiety).

The electrical properties of oil depend mainly on its chemical composition. Electrical resistivity and di- electric strength are the main electrical characteristics of a substance. Electrical conductivity of oil is due to the presence of free charges which move under the influence of an electric field, producing an electrical current. Consequently the electric resistivity is the reciprocal of electric conductivity. The electrical properties and qualities attributed to essential oils (flavorings) might be responsible for the aroma therapeutic capabilities attributed to them [11].

They may also provide scientific explanations for some traditional or cultural practices of water treatment seen in some African localities. The Indigenous people had a practice of incinerating the pod of 'uhiokirihio' in ceramic wares. After the incineration process, the ceramic wares were used in the storage of drink or table water. The water was known to retain the flavor of the incinerated pod for up to seven days. Such plant extracts were also associated with anti microbial effects. Charcoal from hardwoods were employed during such incineration practices. After the incineration and thorough washing of the pot, drink or table water that was stored in the pot (covered), extracted and retains the flavor of the incinerated plant material (at least seven days after).

This principle might be similar to what obtains in ion exchange chromatography, electropositive and electronegative bodies (charged moieties like those of essential oil/flavor components) are carried or attached to supports (like ceramic beads etc.) and can be desorped or detached when suitable solvents are applied. Studies by $[1,3,4,12]$ all attested to minimum toxicity of properly kilned earthenware.

There is a lot of value and acceptability placed on the aroma/flavor as well as the medicinal/ neutraceutical potentials of Ociimumgratissium; enough to warrant this research effort aimed at extracting and quantifying a chlorophyll free flavor solution of this leave for possible incooperation into appropriate food preparations (www.awaycande.com). Pigment free flavor extracts (of known and acceptable concentrations) from GRAS (generally regarded as safe) materials, will continue to be highly valuable in the food and pharmaceutical industries.

\section{Materials and Methods}

This is a modification of cultural technique or procedure practiced in Umuahia, metropolis in Abia state, South-east of Nigeria. The 'Nchuanwu' leaves (50g), picked from the plant without the leave-stock were incinerated using $50 \mathrm{~g}$ of commercial charcoal for $24 \mathrm{hrs}$ while enclosed in a clay pot $(8 \mathrm{~cm}$ diameter and $9 \mathrm{~cm}$ in height). The clay pot (after incineration) was rinsed with $500 \mathrm{ml}$ of table water. Then $200 \mathrm{ml}$ of table water was poured into the pot, covered and allowed to stand in a cool place. Starting with the day of treatment as day one, samples were withdrawn for five days for analysis. Degree brix, $\mathrm{pH}$, absorptivity and specific gravity of the samples were assessed. Sensory evaluation was employed in the comparison of degree of flavor retention, color and overall acceptability among samples. In the second procedure, basil leaves collected as in the first procedure were in separate batches stuffed into the distillation bottle with $200 \mathrm{ml}$ of distilled water. Distillation was carried out for 2 hours and distillates collected and stored in tightly sealed plastic bottle labeled as subunits of sample B [10].

The flavor extracts (sample A - prepared by a modification of traditional water treatment practice; sample B - prepared by distillation) were subjected to sensory evaluation using a 20 man trained panelist with the fresh leaf as control. The parameters compared are intensity of 'nchuanwu' flavor, interference by other flavors example chlorophyll, color and overall acceptability.

Employing an electric circuit comprised of voltmeter, ammeter and Resistor. The following parameters were assessed for samples A and B; electrical resistance and conductivity at a fixed voltage. In addition, density, specific gravity, Total soluble solids (TSS) and $\mathrm{pH}$ of the samples were assayed according to the specified methods.

\section{Results}

The flavor intensity $\mathrm{F}$ for $\mathrm{A}$ (prepared by modified traditionalmethod) was 8 and was not significantly different from that of $\mathrm{B}$ and the control (natural leave) which were respectively 7 and 10 . In terms of interference however, sample B gotten by distillation had some after taste effect traceable to chlorophyll which perhaps made it less acceptable (5) compared to (9) higher acceptability of A (see table 1)

The electrical conductivity for ' $200 \mathrm{~g}$ leave $/ 500 \mathrm{ml}$ water' sample was 133 while that of ' $25 \mathrm{~g}$ leave $/ 500 \mathrm{ml}$ water' was 96. The corresponding resistances to flow of electricity were respectively 4.77 and 5.58 . With the $\mathrm{B}$, the resistances to flow of electricity were respectively 4.66 and 4.95 for $200 \mathrm{~g}$ leave and $20 \mathrm{~g}$ leave.

\section{Discussions}

Resistance to flow of electricity seems to be decreasing with increasing concentration of leaf/ flavor extract though slowly but steadily, giving a low gradient of 0.001 (Tables 2 and3). The same trend applied to TSS and $\mathrm{pH}$. Temperature during reaction, had an opposite trend; reducing with reducing concentration. It might be that ionization was reducing which is in agreement with the reducing TSS and flow of electric current. From a standard graph of electrical resistance versus concentration of flavor concentration, it is possible to calculate the flavour concentration of new preparations Souad et al [11] also highlighted this direct relationship between flavor concentration and resistivity to flow of electricity. This fact, coupled with the $8 / 10$ sensory evaluation score (for flavour intensity) made by the extract from the modified traditional method (Table 2), portrays this method as one with great potential for the food and pharmaceutical industry [7]. 


\section{Conclusion and Recommendation}

Research works that are based on original and cultural ideas and practices, should be supported by the international community. It has a greater potential of good results and hence benefit to mankind since issues of health hazard might not be critical having been practiced for long (centuries in some cases) among a large population. In the chance that such practices scientifically predisposes to some other remarkable forms of health hazards, there is need for early enough warning.

This research has demonstrated a practical and relatively cheaper procedure for extraction of colorless (chlorophyll free)flavor from spices and some medicinal herbs by exposing and adopting (after modification) of an age long yet almost undocumented cultural practice.

The work also demonstrated thatfrom a standard graph of electrical conductivities of (water) extracts of (leaves) flavor carrying plant material, versus the quantity of the (leaves) flavor carrying components (in fixed quantity of water) solvent, it is possible to calculate flavor concentrations in the extracts

Therefore, this research has a lot of potentials for the food and pharmaceutical industries $[14,15]$.

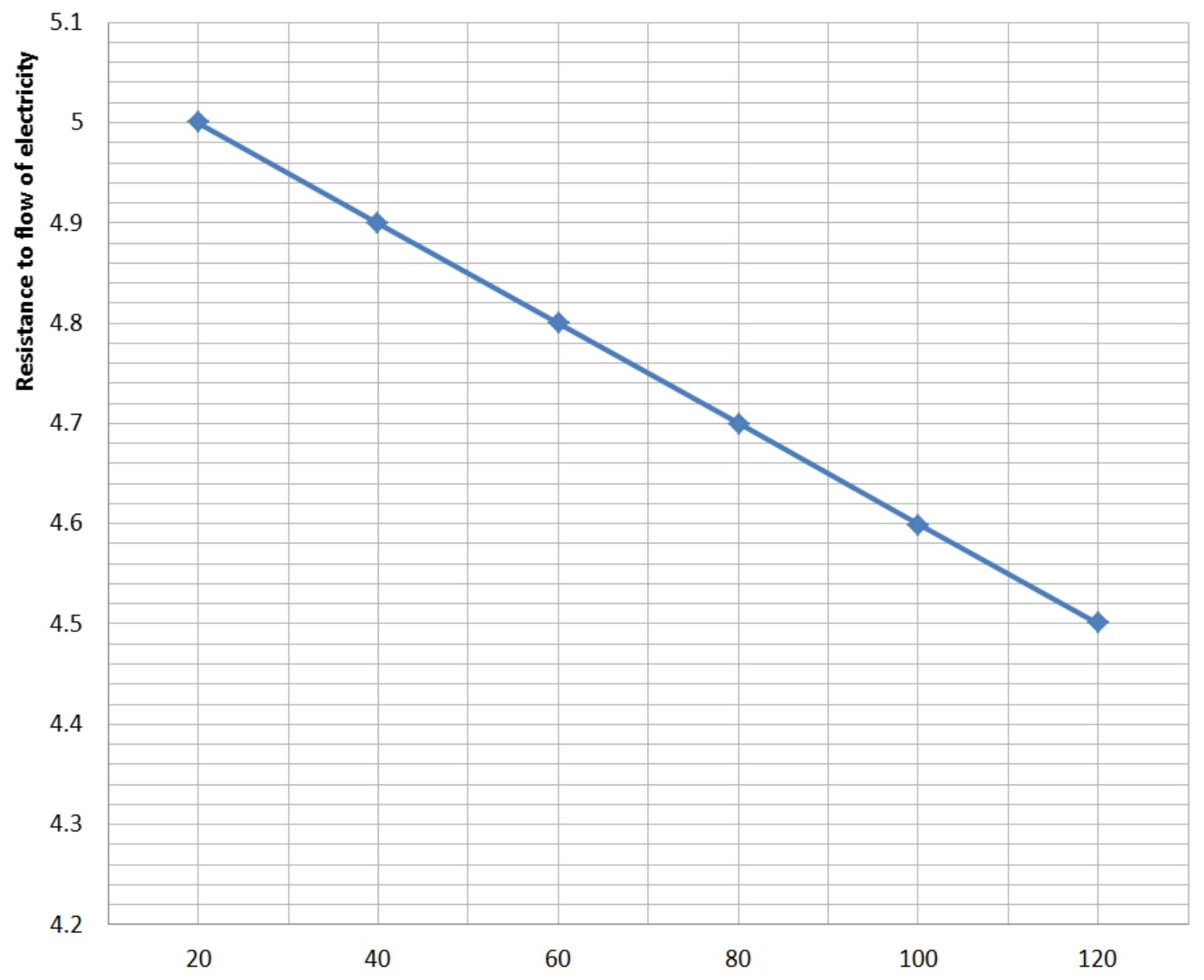

Figure 1. Graph of Concentration against resistance (from sample A; Table 2).

Table 1. Sensory evaluation results of flavour extracts from 'Nchuanwu'leaves.

\begin{tabular}{|c|c|c|c|c|}
\hline \multicolumn{5}{|c|}{ Parameters } \\
\hline Samples & $\mathbf{F}_{1}$ & $\mathbf{F}_{2}$ & Colour & $(\mathbf{O A})$ \\
\hline A & $8 \pm 0.50^{\mathrm{a}}$ & $1 \pm 0.1^{\mathrm{a}}$ & $0 \pm 0.1^{\mathrm{a}}$ & $9 \pm 0.9^{\mathrm{a}}$ \\
\hline B & $7 \pm 1.0^{\mathrm{a}}$ & $6 \pm 0.8^{\mathrm{b}}$ & $3 \pm 0.9^{b}$ & $5 \pm 0.8^{c}$ \\
\hline Control & $10 \pm 0.9^{\mathrm{a}}$ & $1 \pm 0.4^{\mathrm{a}}$ & $10 \pm 0.6^{c}$ & 7. $\pm 0.3^{b}$ \\
\hline
\end{tabular}

Mean \pm SD with same superscript across column, are not significantly different $(\mathrm{p} \leq 0.05)$

$\mathrm{F} 1=$ Flavour intensity

$\mathrm{F} 2=$ Flavour Interference

$A=$ 'Nchuanwu' flavour extracted by modified traditional procedure

$\mathrm{B}=$ Nchuanwuflavour extracted by distillation.

$\mathrm{OA}=$ Overall acceptability 
Table 2. Result of Analysis on sample A (flavour extracted by modified traditional practice).

\begin{tabular}{|c|c|c|c|c|c|c|}
\hline \multirow{2}{*}{ Parameters } & \multicolumn{6}{|c|}{ Varying Quantities of leaf (g) } \\
\hline & 0 & 200 & 150 & 100 & 50 & 25 \\
\hline Electrical conductivity & $15 \pm 3^{\mathrm{a}}$ & $133 \pm 0.4^{\mathrm{b}}$ & $101 \pm 0.5^{\mathrm{c}}$ & $100 \pm 0.5^{\mathrm{c}}$ & $98 \pm 0.9^{c}$ & $96 \pm 0.4^{c}$ \\
\hline $\mathrm{pH}$ & $6.7 \pm 0.1^{\mathrm{d}}$ & $7.29 \pm 0.1^{\mathrm{a}}$ & $7.81 \pm 0.3^{\mathrm{b}}$ & $7.19 \pm 0.2^{\mathrm{a}}$ & $7.48 \pm 0.3^{c}$ & $7.33 \pm 0.4^{c}$ \\
\hline TSS & $60 \pm 0.5^{\mathrm{a}}$ & $52 \pm 0.1^{\mathrm{b}}$ & $54 \pm 0.3^{\mathrm{b}}$ & $56 \pm 0.3^{\mathrm{b}}$ & $52 \pm 0.9^{\mathrm{b}}$ & $59 \pm 0.2^{\mathrm{a}}$ \\
\hline Temperature $\left({ }^{\circ} \mathrm{C}\right)$ & $23.4 \pm 0.2^{\mathrm{a}}$ & $23.5 \pm 0.1^{\mathrm{a}}$ & $23.9 \pm 0.2^{\mathrm{a}}$ & $24.7 \pm 0.1^{\mathrm{b}}$ & $22.9 \pm 0.2^{\mathrm{a}}$ & $23 \pm 0.1^{\mathrm{a}}$ \\
\hline Total acidity & 0.0003 & 0.0002 & 0.0002 & 0.0002 & 0.0003 & 0.0002 \\
\hline Resistance $(\Omega)$ & $5.40 \pm 0.1^{\mathrm{a}}$ & $4.77 \pm 0.2^{\mathrm{b}}$ & $4.82 \pm 0.1^{\mathrm{b}}$ & $5.10 \pm 0.3^{\mathrm{a}}$ & $5.30 \pm 0.4^{\mathrm{a}}$ & $5.58 \pm 0.7^{\mathrm{a}}$ \\
\hline Current (A) & $1.48 \pm 0.01^{\mathrm{a}}$ & $1.67 \pm 0.02^{\mathrm{b}}$ & $1.65 \pm 0.01^{\mathrm{b}}$ & $1.63 \pm 0.02$ & $1.51 \pm 0.02^{\mathrm{a}}$ & $1.43 \pm 0.02^{\mathrm{c}}$ \\
\hline Specific gravity & $1.027 \pm 0.02^{\mathrm{a}}$ & $0.95 \pm 0.01^{\mathrm{b}}$ & $0.95 \pm 0.002^{\mathrm{b}}$ & $0.95 \pm 0.001^{\mathrm{b}}$ & $0.93 \pm 0.001^{\mathrm{b}}$ & $0.95 \pm 0.001^{b}$ \\
\hline
\end{tabular}

Mean \pm SD with same superscript across row are not significantly different $(\mathrm{p} \leq 0.05)$

Table 3. Result of Analysis on sample B (flavour extracted by Distillation)

\begin{tabular}{|c|c|c|c|c|c|c|c|c|c|c|c|}
\hline \multirow{2}{*}{ Parameters } & \multicolumn{11}{|c|}{ Varying Quantities of leaf (g) } \\
\hline & 0 & 200 & 180 & 160 & 140 & 120 & 100 & 80 & 60 & 40 & 20 \\
\hline Electrical conductivity & $10 \pm .1^{\mathrm{a}}$ & $110 \pm .9^{\mathrm{b}}$ & $117 \pm .1^{\mathrm{b}}$ & $110 \pm .1^{\mathrm{b}}$ & $114 \pm .1^{\mathrm{b}}$ & $113 \pm .1^{\mathrm{b}}$ & $104 \pm .2^{c}$ & $132 \pm .2^{\mathrm{d}}$ & $112 \pm .1^{b}$ & $136 \pm .1^{\mathrm{d}}$ & $133 \pm .1^{\mathrm{d}}$ \\
\hline $\mathrm{PH}$ & $6.7 \pm 0.1^{\mathrm{a}}$ & $7.09 \pm .2^{\mathrm{b}}$ & $7.06 \pm .1^{\mathrm{b}}$ & $7.14 \pm .2^{\mathrm{c}}$ & $7.18 \pm .1^{\mathrm{c}}$ & $7.33 \pm .2^{\mathrm{c}}$ & $7.03 \pm .1^{\mathrm{b}}$ & $7.08 \pm .3^{\mathrm{b}}$ & $7.15 \pm .1^{\mathrm{c}}$ & $7.02 \pm .1^{\mathrm{b}}$ & $7.29 \pm .2^{\mathrm{c}}$ \\
\hline Temperature $\left({ }^{\circ} \mathrm{C}\right)$ & $26 \pm .2^{\mathrm{a}}$ & $26 \pm .1^{\mathrm{a}}$ & $25.9 \pm .2^{\mathrm{a}}$ & $25.5 \pm .3^{\mathrm{a}}$ & $25.9 \pm .1^{\mathrm{a}}$ & $25.9 \pm .1^{\mathrm{a}}$ & $25.8 \pm .2^{\mathrm{a}}$ & $25.8 \pm 0.3^{\mathrm{a}}$ & $25.3 \pm 0.1^{\mathrm{b}}$ & $25.8 \pm .1^{\mathrm{a}}$ & $25.8 \pm 0.1^{\mathrm{a}}$ \\
\hline Total acidity & 0.0003 & 0.0002 & 0.0002 & 0.0002 & 0.0002 & 0.0002 & 0.0002 & 0.0002 & 0.0002 & 0.0001 & 0.0001 \\
\hline Resistance $(\Omega)$ & $4.66 \pm .5^{\mathrm{a}}$ & $4.68 \pm .1^{\mathrm{a}}$ & $4.74 \pm .3^{\mathrm{a}}$ & $4.75 \pm .2^{b}$ & $4.77 \pm .8^{\mathrm{b}}$ & $4.78 \pm .1^{\mathrm{b}}$ & $4.81 \pm 0.1^{\mathrm{b}}$ & $4.86 \pm .1^{\mathrm{c}}$ & $4.89 \pm 0.5^{\mathrm{c}}$ & $4.90 \pm 0.9^{c}$ & $4.95 \pm 1.0^{\mathrm{c}}$ \\
\hline Current (A) & $1.72 \pm .01^{\mathrm{a}}$ & $1.70 \pm 002^{\mathrm{a}}$ & $1.89 \pm .01^{\mathrm{b}}$ & $1.68 \pm .01^{\mathrm{a}}$ & $1.68 \pm .02^{\mathrm{a}}$ & $1.67 \pm .01^{\mathrm{a}}$ & $1.66 \pm .03^{\mathrm{c}}$ & $1.65 \pm .01^{\mathrm{c}}$ & $1.64 \pm 0.03^{\mathrm{c}}$ & $1.63 \pm 0.06^{\mathrm{c}}$ & $1.62 \pm 0.05^{\mathrm{c}}$ \\
\hline Brix $^{0}$ & 0 & 0 & 0 & 0 & 0 & 0 & 0 & 0 & 0 & 0 & 0 \\
\hline Specific gravity & $1.027 \pm .002^{\mathrm{b}}$ & $0.95 \pm .003^{\mathrm{b}}$ & $0.95 \pm .003^{\mathrm{b}}$ & $0.95 \pm .003^{\mathrm{b}}$ & $0.93 \pm .02^{b}$ & $0.95 \pm .01^{\mathrm{b}}$ & $0.95 \pm .0 .1^{\mathrm{b}}$ & $0.93 \pm .01^{b}$ & $0.95 \pm .02^{b}$ & $0.93 \pm .0 .01^{\mathrm{b}}$ & $0.93 \pm 0.1^{\mathrm{b}}$ \\
\hline
\end{tabular}

Mean \pm SD with same superscript across row are not significantly different $(\mathrm{p} \leq 0.05)$

Wight of leaf $(\mathrm{g}) / 500 \mathrm{ml}$ water

$$
\text { Gradient }=\frac{\Delta y}{\Delta x}=0.001
$$

\section{References}

[1] Anderson GL, Garnick L, Fung MS, Gafney SH (2017) A pilot study toassess lead exposure from routine consumption of coffee andtea fromceramic mugs: comparison to California Safe Harbor Levels. International Journal of Food Contamination, Vol. 4.

[2] Aderemi TA, Adenuga AA, Oyekunle JAO, Ogunfowokan AO (2017). High level leaching of heavy metals from colorful ceramic foodwares: apotential risk to human. Environmental Science and Pollution Research;24: 17116-17126.

[3] Ajemba RO (2014) Kinetics and equilibrium modeling of lead (II) andchromium (III) ions' adsorption onto clay from Konobowe, Nigeria. Turkish Journal of Engineering and Environmental Sciences, 38: 455-479.

[4] Boisa N, Bekee D (2017); Leaching of potentially toxic metals (PTMs) from two Nigerian clays and related clay pottery used locally asfood wares. J. Environ Anal. Chemistry 4: 222doi $104172 / 2380-2391.1000222, \mathrm{pg} 3$ of 4 .

[5] De la Campa AMS, de la Rosa JD, González-Castanedo Y, Fernández-Camacho R, Alastuey A, et al. (2010) High concentrations of heavymetals in PM from ceramic factories of Southern Spain. AtmosphericResearch 96: 633-644.

[6] Fandohamp G B, Lateye A., Gbeno J A. (2008). Toxicity and gastric tolerance of essential oils from cymbopogan citrates. Chemicaltoxicology. 46(7):2493 - 2497 doi 101016 J. FCT2008.04.006 PMD 18511170.
[7] Health benefits of Ocimumgratissimum (Ohamadi). www.awaycande.com/2018/09/7. 30/12/2020

[8] Liao QL, Liu C, Wu HY, Jin Y, Hua M, et al. (2015) Association of soilcadmium contamination with ceramic industry: A case study in aChinese town. Science of the Total Environment 514: 26-32.

[9] Mcbride MB, Blasiak JJ (1979) Zinc and Copper Solubility as a Functionof $\mathrm{pH}$ in an Acid Soil. Soil Science Society of America Journal 43:866-870.

[10] Morris Jacobs (1999). Food Analysis, Hutton educational publishing India. Pgs $727-735$.

[11] SouadAlaoni, Maryam Belghazi, HajarSaaid (2015). Electrical properties of vegetables and essential oils. (www.schorlaresearchlibrary.com) 27/10/2020.

[12] Schnaas L, Rothenberg SJ, Flores MF, Martínez S, Hernández C, et al.(2004) Blood Lead Secular Trend in a Cohort of Children in Mexico City(1987-2002). Environmental Health Perspectives 112: 1110.

[13] Jurinak JJ, Jerorne DW (1955) Zinc Solubility Under Alkaline Conditionsin a Zinc-Bentonite System. Soil Science Society of America Journal 19:446-448.

[14] B A Iwalokun, G O Gbenle, T A Adewole, S I Smith, K A Akinsinde and E O Omonighehin (2003). Effects of ocimum gratissium on virulent and multi drug resistant shigella strains from Lagos Nigeria. APMIS 111 - 477 - 82. ISSN 0903 4641 .

[15] Sylvester Ohadoma, Louise U. Enye, Chris. E. Okolo (2015). Comparative analysis of Therapeutic benefits of ocimum gratissimium. European Journal of pharmaceutical and Medical research. www.ejpmr.com. 